\title{
Diflorasone Diacetate
}

\author{
National Cancer Institute
}

\section{Source}

National Cancer Institute. Diflorasone Diacetate. NCI Thesaurus. Code C47488.

The acetate salt form of diflorasone, a synthetic glucocorticoid with anti-inflammatory and immunosuppressive properties. Like other glucocorticoids, diflorasone enters the cell by diffusion across the cell membrane and binds to the glucocorticoid receptor (GR) in the cytoplasm. The receptor complex subsequently translocates to the nucleus and activates or represses genes by interacting with short, palindromic DNA sequences called glucocorticoid response element (GRE). Gene activation leads to the exertion of antiinflammatory effects, e.g. upregulation of IkappaB, while gene repression inhibits production of pro-inflammatory cytokines such as interleukin-1 (IL-1), IL-2 and IL-6, thereby preventing activation of cytotoxic T-lymphocytes. 